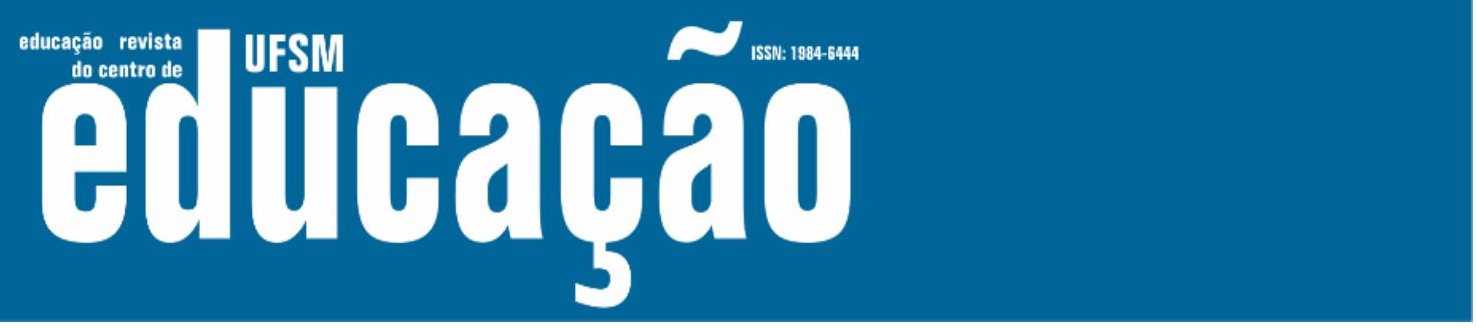

ISSN: 1984-6444 | http://dx.doi.org/10.5902/1984644438651

\title{
Internacionalização da educação e dos currículos nos contextos do Ensino Básico e Secundário em Portugal.
}

Internationalization of education and curriculums in the contexts of Basic and Secondary Education in Portugal

Juares da Silva Thiesen

Professor Associado da Universidade Federal de Santa Catarina, Florianópolis, Santa Catarina, Brasil. juares.thiesen@ufsc.br - http://orcid.org/0000-0001-9299-4441

Filipa Seabra

Professora da Universidade Aberta, Porto, Portugal.

filipa.seabra@uab.pt - https://orcid.org/0000-0003-1690-9502

Recebido em 20 de junho de 2019

Aprovado em 04 de fevereiro de 2020

Publicado em 25 de setembro de 2020

\section{RESUMO}

O trabalho resulta de investigação desenvolvida no Instituto de Educação da Universidade do Minho e tem por objetivo analisar os impactos dos movimentos de internacionalização da educação sobre a formulação das políticas curriculares no âmbito do ensino básico e secundário em Portugal. Como recorte da pesquisa mais ampla, caracteriza-se, no texto, o atual quadro de (re)formulação da política curricular portuguesa para estes níveis de ensino, com especial atenção às evidências de alinhamento e adesão às demandas dos movimentos transnacionais que se colocam em defesa da internacionalização da educação. O pressuposto é que Portugal, assim como muitos outros países, sofre os efeitos da regulação transnacional que atua na direção da desnacionalização das políticas educativas. Trata-se de um trabalho empírico-teórico que explora textos oficiais da política curricular portuguesa e outros estudos relacionados ao tema. A investigação revela que a atual política curricular para o ensino básico e secundário português está fortemente subordinada às recomendações internacionais, especialmente as emanadas da Comunidade Europeia e da OCDE.

Palavras chave: Currículo; Internacionalização; Ensino Básico e Secundário. 


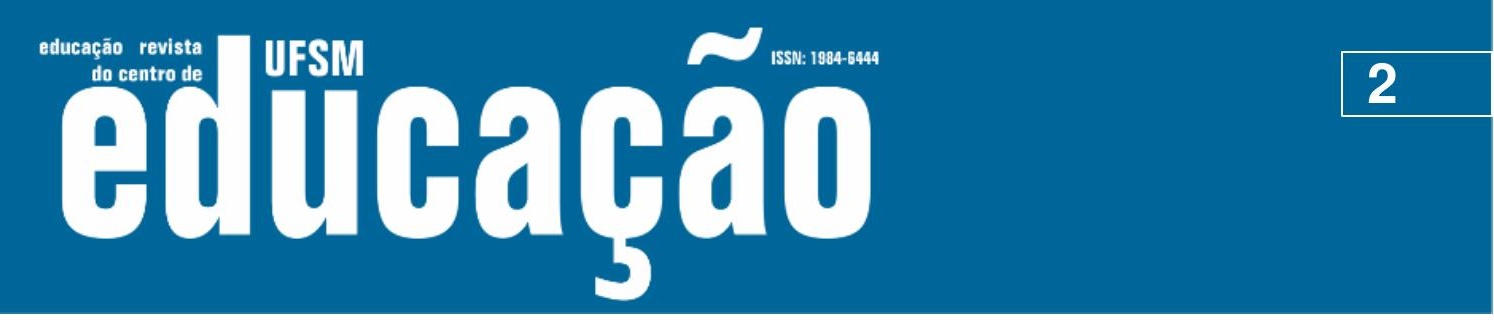

ISSN: 1984-6444 | http://dx.doi.org/10.5902/1984644438651

\section{ABSTRACT}

This study is the result of research conducted at the Institute of Education of the University of Minho. Its objective is to analyze the influence of movements for the internationalization of education on curriculum policies in basic and secondary education in Portugal. Part of a broader study, this paper focuses on the current situation of the (re)formulation of Portuguese curriculum policy for these levels of schooling, with special attention to evidences of alignment and adhesion to the demands of the transnational movements that defend internationalization of education. It is understood that Portugal, like many other countries, suffers from the effects of transnational regulation that drives the denationalization of educational policies. It is an empiric-theoretical study that examines official texts concerning Portuguese curriculum policy and other research related to the issue. The study revealed that the current curriculum policy for basic and secondary education in Portugal is strongly subordinated to international recommendations, especially those from the European Community and the OECD.

Keywords: Curriculum; Internationalization; Basic and Secondary Education.

\section{Introdução}

Em épocas de rápidas mudanças sociais, económicas e políticas, as referências internas são insuficientes para justificar a persistência ou a introdução de reformas. É precisamente nesses momentos que a externalização oferece a oportunidade de romper radicalmente com 0 passado e importar, ou tomar como empréstimo, modelos, discursos ou práticas de outros sistemas educativos (Steiner-Khamsi, 2002, p. 70).

Julgamos a afirmação de Steiner-Khamsi adequada para introduzir a problemática que se pretende discutir e aprofundar no texto, cujo objetivo é explorar evidências de alinhamento da atual política curricular portuguesa para o ensino básico e secundário com as demandas das redes políticas e organismos transnacionais que se colocam em defesa da chamada internacionalização da educação. Com esse propósito, recorre-se ao atual quadro de (re)formulação e desenvolvimento da política curricular portuguesa nestes níveis de ensino para identificar aspectos de alinhamento e adesão do referido sistema educativo às recomendações, requerimentos e modos de regulação e controle instituídos em espaços extra ou supranacional.

A premissa que serve de base para a análise da relação é que Portugal, assim como muitos outros países, sofre os efeitos de uma regulação transnacional que atua 


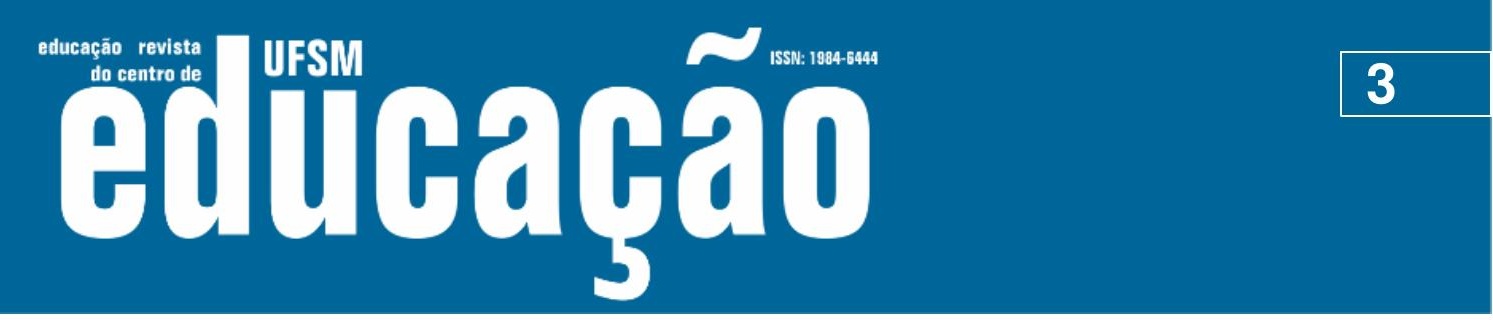

ISSN: 1984-6444 | http://dx.doi.org/10.5902/1984644438651

no sentido da desnacionalização ${ }^{1}$ das políticas educativas, cenário no qual as (re)formulações curriculares passam a contar com forte influência e/ou participação de decisores externos.

Os referenciais teóricos que amparam argumentos aqui colocados e defendidos são essencialmente de trabalhos já realizados por pesquisadores que analisam a problemática da transnacionalização e internacionalização da educação com foco na realidade portuguesa; textos de documentos oficiais da política educacional e curricular do Sistema de Ensino Português; documentos de organismos multilaterais que, de algum modo, tratam sobre a problemática em pauta; textos de documentos produzidos por organismos da União Europeia e, ainda, textos que organizamos sobre essa mesma pesquisa quando foram analisados os movimentos de internacionalização dos currículos nos contextos da Educação Básica brasileira².

Trata-se, pois, de um trabalho empírico-teórico que toma a produção científica já existente como fonte primária para selecionar e analisar alguns de seus conteúdos com vistas a explorar suas relações e formular novas sínteses como produto de conhecimento. Desse modo, apresenta-se, inicialmente, breve contextualização da problemática, destacando-se algumas evidências relacionadas com internacionalização dos currículos já identificadas no âmbito dessa pesquisa. $\mathrm{Na}$ sequência, situam-se os contextos transnacionais nos quais são mobilizados projetos em perspectiva de internacionalização da educação e dos currículos em Portugal e finalmente destacam-se marcas de alinhamento e de adesão da política curricular do ensino básico e secundário de Portugal com movimentos transnacionais pela internacionalização.

\section{Breves notas com evidências sobre o movimento da internacionalização da educação e dos currículos.}

Como fizemos referência, o percurso de pesquisa desenvolvido até aqui revelou uma série de evidências, algumas das quais estão destacadas a seguir como sínteses ou resultados parciais que ajudam a situar e compreender aspectos importantes sobre os movimentos transnacionais pela internacionalização em 


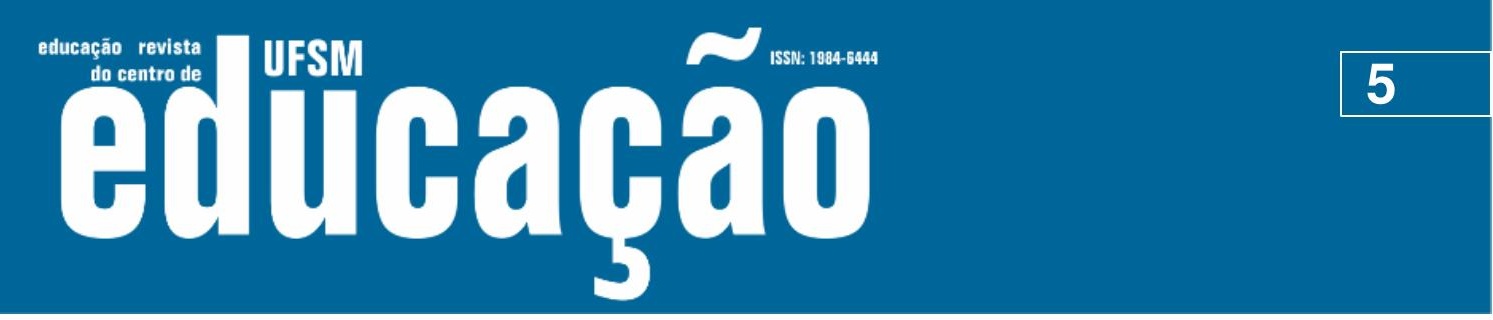

ISSN: 1984-6444 | http://dx.doi.org/10.5902/1984644438651

discursos que ganham hegemonia em instituições educativas e nos espaços de governo e que, por extensão, se expressam com força nos contextos de influência e de produção de textos de políticas (BALL; BOWE, 1992) alcançando os territórios curriculares dos sistemas educativos e das escolas.

Ainda no quadro das evidências, revela-se o significativo poder de influência exercido atualmente pelas chamadas Escolas Internacionais e respectivas redes não estatais que as gerenciam. Os bons indicadores de resultados alcançados pelas escolas classificadas com essa tipologia nos rankings das performances escolares com seus respectivos instrumentos de credenciamento e acreditação como é, por exemplo, o International Baccalaureate - IB-DP, vêm fortalecendo ainda mais o discurso da internacionalização. Além de uma vertiginosa expansão quantitativa na oferta de escolas internacionais pelos quatro cantos do mundo, faz-se um amplo trabalho de disseminação de seu alto desempenho curricular, aspecto que vem repercutindo fortemente nas decisões curriculares no âmbito dos sistemas de ensino.

Tendo em conta esse conjunto afirmações de caráter contextual, passamos a apresentar e discutir aspectos da relação do sistema de ensino básico e secundário português com as racionalidades, expectativas, requerimentos e demais demandas dos projetos transnacionais de internacionalização da educação e dos currículos. Com esse propósito, situamos os contextos transnacionais nos quais a educação portuguesa se alinha e se integra para em seguida apontarmos o envolvimento mais específico do ensino básico e secundário português com esse mesmo movimento.

\section{Contextos transnacionais de internacionalização: influências educacionais e curriculares em Portugal}

É significativo o volume de trabalhos e de pesquisadores dedicados ao tema ou a problemática da internacionalização da educação e dos currículos em Portugal. Assim como ocorre no Brasil, constata-se que as pesquisas envolvem essencialmente o âmbito da Educação Superior, sendo mais raros os trabalhos que abordam alguma relação entre os currículos do ensino básico e secundário com concepções, expectativas ou requerimentos da internacionalização. 


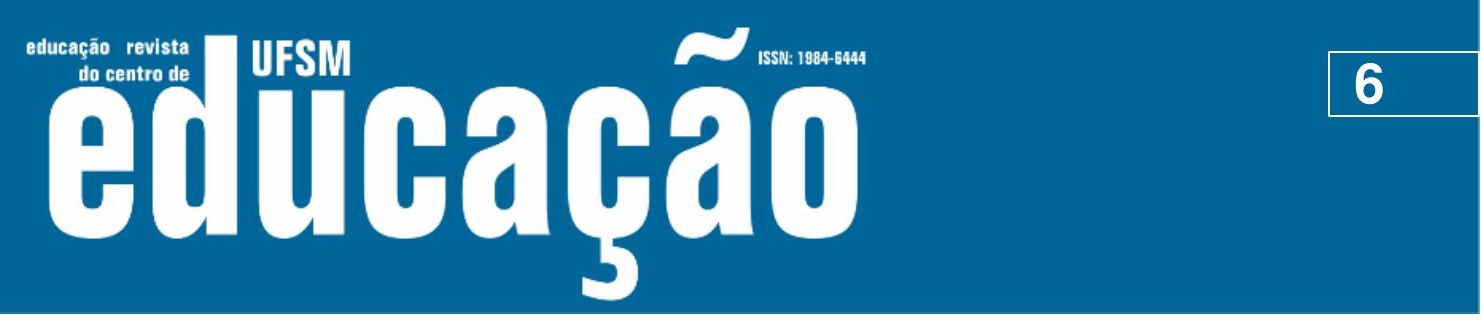

ISSN: 1984-6444 | http://dx.doi.org/10.5902/1984644438651

Por meio de busca às bases de dados especialmente em livros, periódicos e pesquisas de programas stricto sensu produzidas em Portugal, foi possível visualizar um panorama da produção científica envolvendo tanto a problemática da internacionalização da educação em geral quanto do ensino básico e secundário em particular ${ }^{5}$. Grosso modo, essa produção mostra-se especialmente voltada à investigação do tema em quatro recortes distintos que os caracterizo como: i) trabalhos sobre internacionalização na educação em contexto geral; ii) trabalhos sobre internacionalização do/no Ensino Superior em Portugal; iii) trabalhos sobre a relação entre o sistema de ensino básico e secundário português e o contexto internacional, e, iv) trabalhos que analisam documentos da política curricular para o ensino básico e secundário de Portugal. É, pois, desse referencial que se extrai os principais elementos tanto para a análise da integração do sistema educativo português aos contextos transnacionais em termos socioeconômicos e políticos mais amplos, quando dos vínculos mais particulares do ensino básico e secundário.

Como não se revela diferente, é no mesmo contexto socioeconômico e político no qual se encontram evidências de alinhamento de muitos sistemas educativos nacionais aos requerimentos da governação transnacional com a pauta da internacionalização que se insere o sistema português relativamente à educação em geral e ao ensino básico e secundário em particular.

Portugal, segundo Santos (2001) e Hespanha (2001) está colocado na órbita da transnacionalização por razões que incluem sua posição como ex-império colonial exercendo, ainda, forte influência, sobretudo no campo educativo e curricular de países africanos de língua portuguesa (PALOPs); por apresentar-se como um país semiperiférico do sul da Europa com indicadores educacionais e econômicos abaixo da média europeia, portanto vulnerável às influências das formas e modelos hegemônicos externos e, obviamente, por sua franca integração e subordinação às regras internacionais, nomeadamente da União Europeia - comunidade transnacional da qual emanam orientações e recomendações para seus respectivos sistemas de ensino.

De modo geral, observa-se que as principais iniciativas envolvendo o atual projeto político de internacionalização da educação em Portugal estiveram 


\section{T- ussm

ISSN: 1984-6444 | http://dx.doi.org/10.5902/1984644438651

espaços supranacionais e é sustentada pelos discursos hegemônicos da internacionalização.

Trata-se, pois, de um discurso que carrega consigo o imperativo de uma educação global e que demanda aos sistemas nacionais a prescrição de currículos, em geral, orientados com base na aquisição de competências interculturais e globais, mantendo-se a responsabilização e a regulação nos estados por meio da avaliação de resultados.

Tendo em conta esse contexto e com inspiração, sobretudo nas reflexões de Barroso (1988; 2003) sobre esse sistema de influências, busca-se mostrar na figura a seguir, aspectos dessa racionalidade.

Figura 1 - Contextos de regulação, controle e contaminação em escala transnacional.

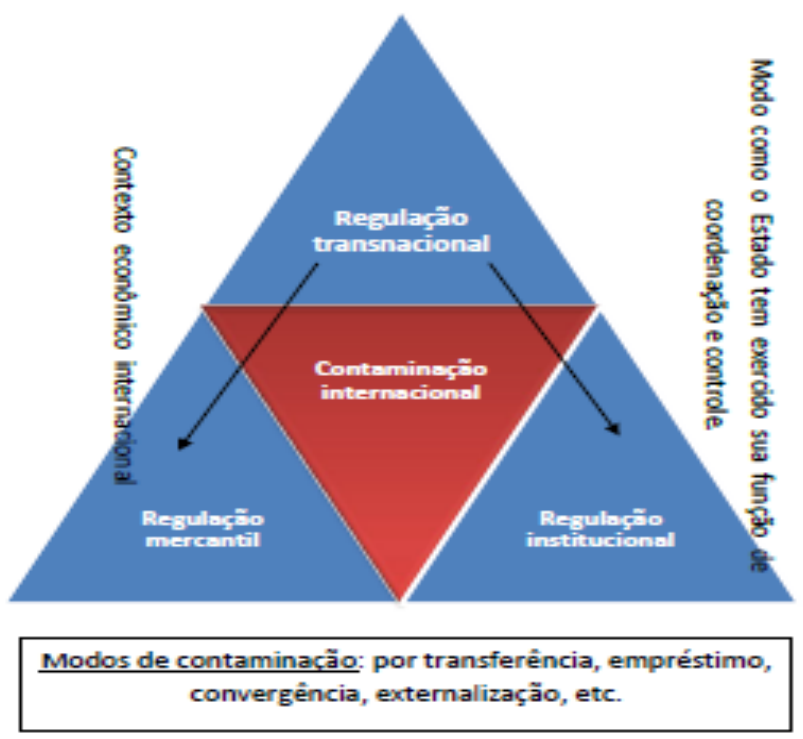

Fonte: Produção livre dos autores, 2018.

Advertências sobre essa lógica de escala supranacional que vem tomando significativa parcela da vida social nos âmbitos público e privado e que tem na educação seu imperativo maior, é feita por vários outros pesquisadores portugueses. 


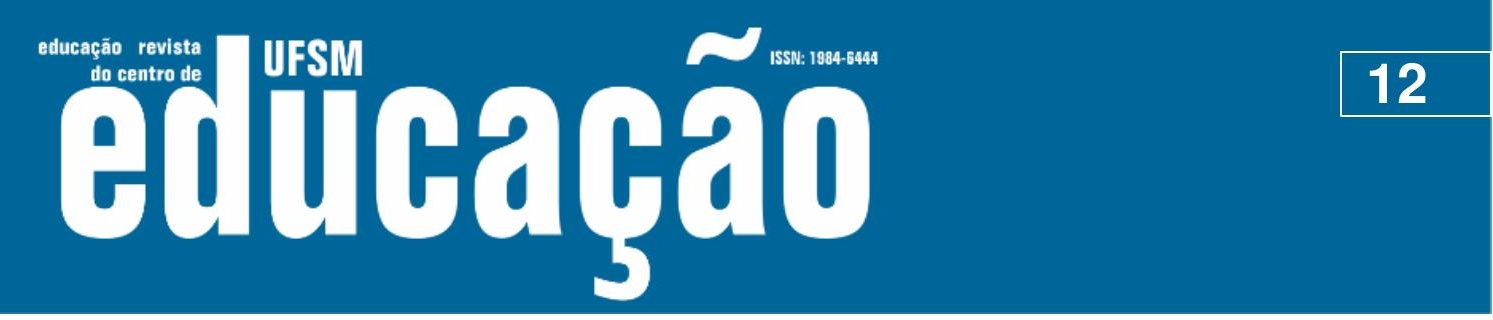

ISSN: 1984-6444 | http://dx.doi.org/10.5902/1984644438651

\section{Alinhamentos com movimentos pela internacionalização no âmbito do Ensino Básico, Secundário e Profissional em Portugal}

Distintamente do que ocorre na Educação Básica no Brasil onde o alinhamento ao internacional se dá de modo mais sutil, em Portugal a relação de vínculos é aberta e explicitada, inclusive, em textos de documentos oficiais da política curricular para os ensinos básico, secundário e profissional como mostrarei a seguir. Outra diferença é que, enquanto o Brasil estabelece relações de aproximação e acatamento de recomendações/orientações internacionais mais dispersivamente com espaços, redes e organismos transnacionais, Portugal concentra seu regime de subordinação à União Europeia sob forte influência da Organização para a Cooperação e Desenvolvimento Econômico - OCDE.

Tendo em conta que esses vínculos de influência, de recontextualização e de adesão se expressam predominantemente nos contextos de produção dos textos da política educacional e curricular (BALL; BOWE, 1992), passamos a destacar algumas das evidências mais objetivas por meio da exploração de documentos recentemente formulados (últimos três anos) no âmbito dos órgãos centrais do governo português ${ }^{11}$, mais precisamente os produzidos sob coordenação da Direção Geral da Educação no Ministério da Educação e do Conselho Nacional de Educação - CNE. A opção pela consulta de documentos dos últimos três anos deve-se ao fato de as ações de ambos os órgãos constituírem o que o governo chama de sétima revisão curricular ${ }^{12}$ do ensino básico e secundário.

De fato, os três últimos anos, têm se mostrado particularmente importantes no âmbito das definições curriculares para o ensino básico e secundário de Portugal. Associado ao conjunto das (re)formulações curriculares que vem se efetivando em contextos mais amplos e acolhendo recomendações da União Europeia, o Governo, por intermédio da Direção Geral de Educação (DGE) do Ministério da Educação em articulação com o Conselho Nacional de Educação $(\mathrm{CNE})^{13}$, vêm promovendo uma "ampla discussão pública sobre a definição do currículo para o Século XXI, no quadro de uma escolaridade obrigatória alargada a 12 anos" (PORTUGAL, Ministério da Educação DGE, 2017f). 


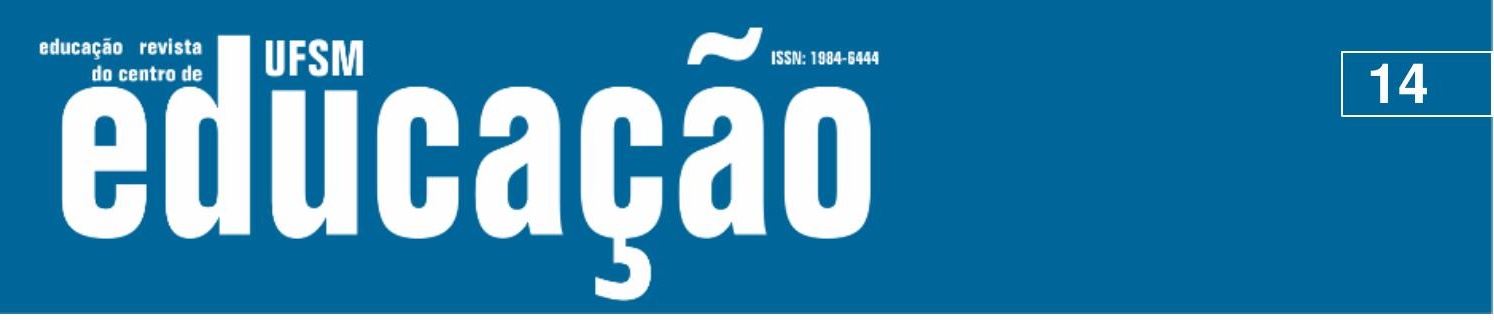

ISSN: 1984-6444 | http://dx.doi.org/10.5902/1984644438651

básica e secundária portuguesa seja com a União Europeia, com a Organização das Nações Unidas (ONU) - com destaque para a UNESCO, ou com a OCDE.

Constata-se, portanto, que as atuais definições do Estado português para a política curricular do ensino básico e secundário são explicitamente sustentadas por concepções e recomendações internacionais. Exemplo de reafirmação da posição do Conselho Nacional de Educação é claramente destacada no texto introdutório do documento Perfil dos alunos à saída da escolaridade obrigatória (PORTUGAL, Ministério da Educação, 2017e, p.10) que assim se coloca:

Para a elaboração do Perfil dos Alunos foi essencial a consulta de referenciais internacionais sobre ensino e aprendizagem ${ }^{19}$, nomeadamente da União Europeia, da Organização para a Cooperação e Desenvolvimento Económico e da Organização das Nações Unidas para a Educação, Ciência e Cultura, bem como a revisão da literatura produzida no campo da investigação em educação, sobre, designadamente, as competências que as crianças e os jovens devem adquirir como ferramentas indispensáveis para o exercício de uma cidadania plena, ativa e criativa na sociedade da informação e do conhecimento em que estamos inseridos. Foram também tidos em consideração documentos análogos de diversos países, textos educativos de âmbito nacional $e$ textos orientadores de entidades europeias e internacionais.

O reforço dessa relação com o extranacional segue sendo destacado em outros textos nesse mesmo âmbito, a exemplo do documento Currículo do ensino básico e do ensino secundário para a construção de aprendizagens essenciais baseadas no perfil dos alunos (PORTUGAL, Ministério da Educação, 2017c), que na introdução acentua o seguinte:

No final do século XX e início do novo milénio, as políticas curriculares
internacionais (dirigidas sobretudo à adequação das respostas curriculares à
diversidade dos contextos pós-massificação e à garantia de índices de maior
eficácia educativa generalizada) geraram, assim, transformações curriculares
de natureza diversa, orientadas por lógicas de "binómio curricular"(Roldão,
$2008 ;$ OCDE 2013), que procuram, no essencial, harmonizar uma prescrição
nacional comum com a autonomia curricular das escolas para decisões
curriculares contextualizadas. (...) Os documentos curriculares de todas as
disciplinas e áreas, numa perspetiva de currículo futuro, atualizada pelos
referentes internacionais (Projeto Educação 2030 , OCDE, 2016; Repensar a
Educação, UNESCO, 2016; Resumo de Políticas, UNESCO, 2017) tendem,
no plano das reconfigurações em curso noutros países, a evoluir para um
formato menos prescritivo, mas mais orientativo (PORTUGAL, Ministério da
Educação, 2017c p. 3-4). 


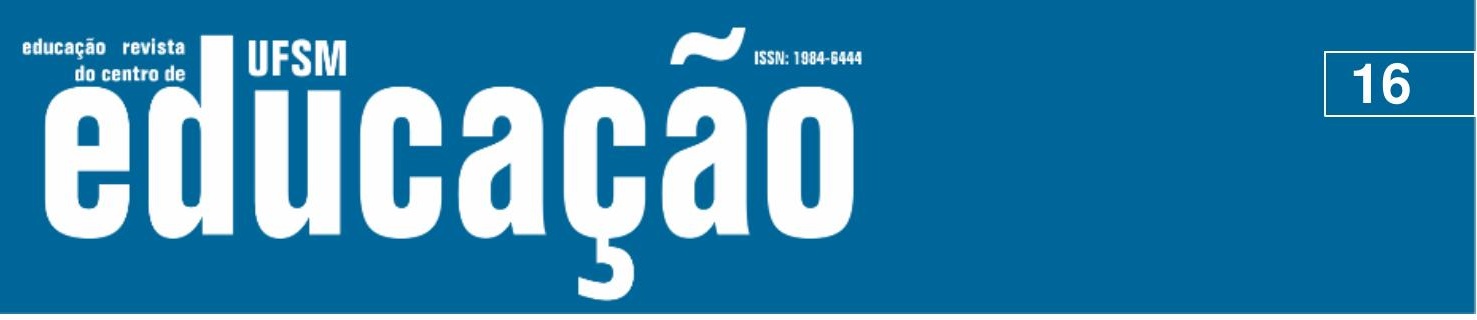

ISSN: 1984-6444 | http://dx.doi.org/10.5902/1984644438651

O papel desempenhado por organizações transnacionais como é o caso do Conselho da Europa, da Comissão Europeia, da OCDE ou da UNESCO, para apenas citar os mais importantes num quadro cada vez mais explícito de competição entre Estados e da sua mobilização para padrões de convergência organizacional, proporcionou uma reconceptualização dos instrumentos ao dispor das políticas educativas que não se limita a uma mera cosmética semântica. São noções que traduzem conceções, ideias e propósitos, que se inscrevem em novas matrizes culturais, senão mesmo, visões do mundo e ideologias.

Ainda no referido documento, na seção de audição de ex-ministros, Diamantino Durão (Ministro da Educação entre 1991 e 1993) diz o seguinte: "Outro aspeto que gostaria de mencionar é a internacionalização. Penso que Portugal deve dar mais atenção a este aspeto, nomeadamente quanto ao ensino de línguas estrangeiras no secundário, pois é importante a troca de conhecimentos e os intercâmbios de alunos e docentes. (...) Portugal, no meu entender, deve continuar a apostar neste tipo de ligações internacionais" (CONSELHO NACIONAL DE EDUCAÇÃO, 2017a, p.90).

A reafirmação da importância da internacionalização é também destacada no capítulo Currículo e conhecimento, notadamente nos tópicos dos componentes curriculares. Na matemática, apenas para citar um exemplo, destaca-se a problemática do rendimento escolar predominantemente com base em estudos e padrões internacionais e consequentemente sem consideração às demandas e especificidades nacional e locais. Nesse âmbito, recorre-se aos tradicionais mecanismos de avaliação (TIMSS, PISA, National Mathematics Advisory Board, etc) para a análise do quadro curricular atual em Portugal. E seus autores concluem o documento afirmando que a grande maioria das recomendações pode ser facilmente transposta para outras realidades, em particular para a portuguesa. "Com efeito, tal como referimos inicialmente, as ideias para o Ensino da Matemática, elaboradas pelo NCTM no final da década de 1980, encontraram grande aceitação na maioria dos países ocidentais, e as correspondentes características implantaram-se nos respectivos sistemas educativos. Não surpreende assim que os problemas encontrados sejam essencialmente comuns, tal como comuns são as respectivas soluções" (CONSELHO NACIONAL DE EDUCAÇÃO, 2027a, p. 152).

Não obstante haver, no texto do documento, fortes destaques à potência do internacional sobre o sistema educativo português, também se faz críticas 


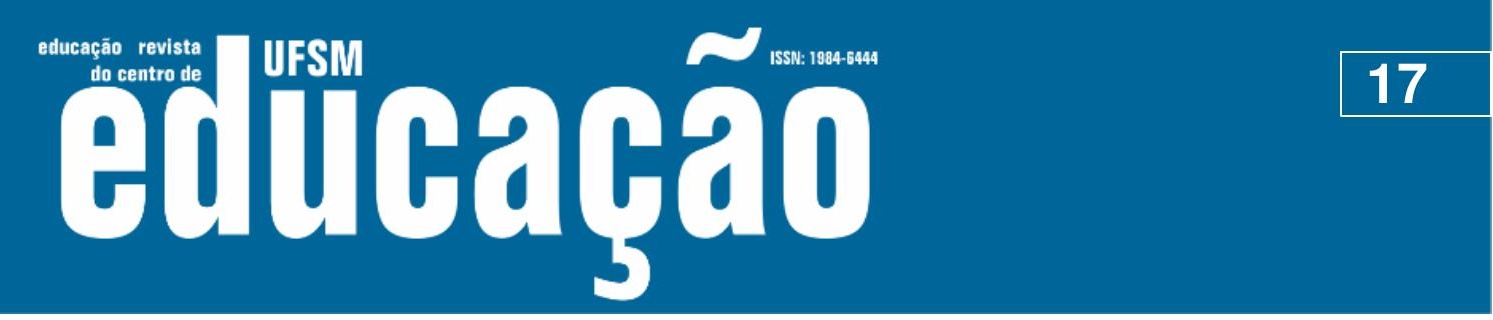

ISSN: 1984-6444 | http://dx.doi.org/10.5902/1984644438651

contundentes. Maria Figueiredo, por exemplo, ao discutir conhecimento e currículo' (CONSELHO NACIONAL DE EDUCAÇÃO, 2017a, p. 307) pondera que: "a atual corrida internacional dos sistemas educativos pela melhoria dos resultados nos testes internacionais parece desprovida de sentido intrínseco, desligada de visões democraticamente desenvolvidas dos futuros cidadãos da nação".

No volume II do mesmo documento (CONSELHO NACIONAL DE EDUCAÇÃO, 2017b), logo na primeira parte, encontra-se o texto de Manuel Braga da Cruz, professor da Universidade Católica Portuguesa que assumindo posição claramente privatista assim se manifesta:

\begin{abstract}
A educação é, seguramente, um bem público, mas que não tem de ser servido pelo Estado. O serviço público de educação pode e deve ser exercido pela sociedade, e só supletivamente pelo Estado. (....) o Estado prodigaliza exclusivamente às suas escolas apoios financeiros de tal grandeza, que recusa às demais escolas, inviabilizando a livre competição entre instituições, e proporcionando a instalação de um protecionismo monopolizador, que em nada favorece a preparação das instituições escolares portuguesas para a competição no espaço europeu e internacional. (...) Portugal precisa de uma escola livre e competitiva, para ter um sistema educativo aberto e internacionalmente competitivo, que contribua de forma decisiva para o seu desenvolvimento e para a sua afirmação internacional (p. 501).
\end{abstract}

Outros dois aspectos que têm se revelado especialmente importantes na política curricular portuguesa são respectivamente o da avaliação e o da qualificação profissional, pautas sobre as quais nota-se, também, forte relação com o contexto internacional em geral e da União Europeia em particular. Sobre avaliação, o DecretoLei $n .917 / 2016$, ao estabelecer os critérios e princípios orientadores para o ensino básico e secundário, reafirma "a necessidade de aprofundar a articulação entre a avaliação externa e a avaliação interna das aprendizagens". E define que "a avaliação constitui um processo regulador do ensino e da aprendizagem, que orienta o percurso escolar dos alunos e certifica as aprendizagens desenvolvidas" (PORTUGAL, Diário da República, Lei 17/2016, 2016, p. 1123).

Sobre qualificação, relativamente à educação profissional, atividade coordenada e regulada por meio da Agencia Nacional para a Qualificação e o Ensino Profissional (ANQEP), importante medida foi tomada pelo governo português em 2017 ao regulamentar, pela Portaria n..$^{47 / 2017}$ de 01/02/2017, o chamado Sistema Nacional de Créditos do Ensino e Formação Profissionais e ao definir, na mesma 


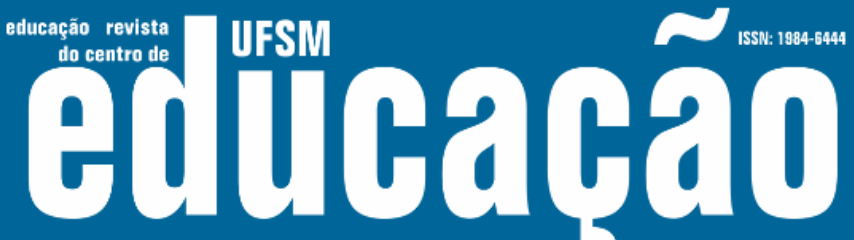

ISSN: 1984-6444 | http://dx.doi.org/10.5902/1984644438651

desafios, mas, na maior parte dos casos, corre atrás de uma mudança que the escapa".

Realçamos, no entanto, que o processo de empréstimo de políticas não é passivo, mas antes estratégico, quer da parte de quem «empresta», quer da parte daqueles que estão no lado da recepção do empréstimo, ocorrem fenómenos de contaminação, hibridismo e mosaico (BARROSO, 2003), levando à recomposição de medidas, bem como a processos de resistência e seleção ativa (STEINER-KHAMSI, 2004), nomeadamente como estratégia de legitimação e externalização de decisões pouco populares por parte dos governos. Importa assim afastar uma noção dos governos locais como meras vítimas de um processo de globalização que thes é exterior, antes abarcando a complexidade dos movimentos estratégicos no contexto nacional, que atuando num cenário de complexidade global crescente, não deixam de ser fundamentais para a compreensão do modo como as políticas e discursos globais em matéria de educação são (ou não) adotados e (re)contextualizados ao nível nacional.

Seguramente a opção política de Portugal pela adesão e consequente acatamento dos mandatos políticos, jurídicos e educacionais instituídos no âmbito da União Europeia no campo da política curricular, constitui apenas um exemplo singular, se considerado o amplo e crescente conjunto de estados nacionais que vem subalternamente submetendo seus sistemas de ensino aos preceitos, critérios e regras desse macro-projeto transnacional chamado internacionalização que impõe ao mundo, pela força de sua hegemonia, a ideia de um único caminho possível para a educação e para a escola: uma formação baseada em competências globais cujo resultado serve fundamentalmente para fortalecer o desenvolvimento econômico.

\section{Referências}

ANTUNES, Fátima. Os locais das escolas profissionais: novos papeis para o Estado e a europeização das políticas educativas. In: STOER, Stephen; CORTESÃO, Luiza;CORREIA, José Alberto. (Orgs). Transnacionalização da educação: da crise da educação à "educação da crise". Porto: Edições afrontamento, 2001, p. 163-208. 


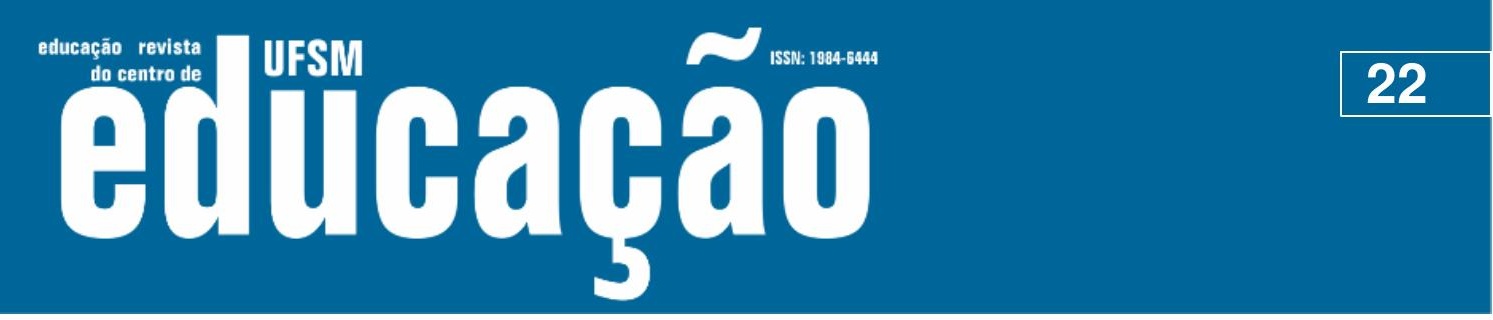

ISSN: 1984-6444 | http://dx.doi.org/10.5902/1984644438651

DALE, Roger. Globalização e educação: demonstrando a existência de uma "cultura educacional mundial comum" ou localizando uma "agenda globalmente estruturada para a educação"? Campinas: Educação e Sociedade, v.25, n.87, p. 423-460, 2004.

DALY, Herman E. Globalization versus internationalization: some implications. New York: Globlization, Penguin books, 2002.

DOLOWITZ, David P.; MARSH, David. Learning from abroad: The role of policy transfer in contemporary policy-making. Governance: An International Journal of Policy and Administration, n.1, p. 5-24, 2000.

FERNANDES, Preciosa. O currículo do ensino básico em Portugal: políticas, perspectivas e desafios. Porto: Editora Porto, Coleção educação e formação, 2011.

HESPANHA, Pedro. Mal estar e risco social num mundo globalizado: Novos problemas e novos desafios para a teoria social. In: SANTOS, B. S. (Org). Globalização, fatalidade ou utopia? Porto: Edições afrontamento, 2001.

JUSTINO, David; BATISTA, Susana. Redes de escolas e modos de regulação do sistema educativo. Évora: Educação, temas e problemas, p. 41-60, 2013.

LEMOS, Valter Victorino. A influência da OCDE nas políticas públicas de educação em Portugal. 2014. Tese (Doutoramento), Instituto Universitário de Lisboa, $2014 . \quad$ Disponível

em:

https://repositorio.iscteiul.pt/bitstream/10071/8434/1/Tese\%20Valter\%20Lemos\%20 \%28\%2B\%20anexos\%20e\%20CV\%29.pdf. Acesso em: 2 mai. 2018.

NÓVOA António. Histoire \& comparaison: essais sur l'educatio. Lisboa: Educa, 1998.

OCDE. Relatórios econômicos da OCDE, resumo executivo. Estudos Económicos da OCDE, Portugal, 2017. Disponível em: https://www.oecd.org/eco/surveys/Portugal2017-OECD-economic-survey-overview-portuguese.pdf. Acesso em: 03 mai, 2018.

PACHECO, José Augusto e PEREIRA, Nancy. Globalização e identidade no contexto da escola e do currículo. Cadernos de Pesquisa, n.131, p. 371-398, 2007.

PACHECO, José Augusto. Políticas de avaliação e qualidade da educação, uma análise crítica no contexto da avaliação externa de escolas, em Portugal. Campinas: Avaliação, n.2, p. 363-371, 2014.

PARLAMENTO EUROPEU. Internacionalização do ensino superior: estudo. Departamento Temático B: Políticas Estruturais e de Coesão, Bruxelas: 2015.

PORTUGAL. Diário da República. Decreto Lei n.17/2016 de 04 de abril. 2016. Disponível em: http://www.dge.mec.pt/sites/default/files/Basico/Legislacao/ decreto_lei_17_2016_0.pdf. Acesso em: 28 abr, 2018. 


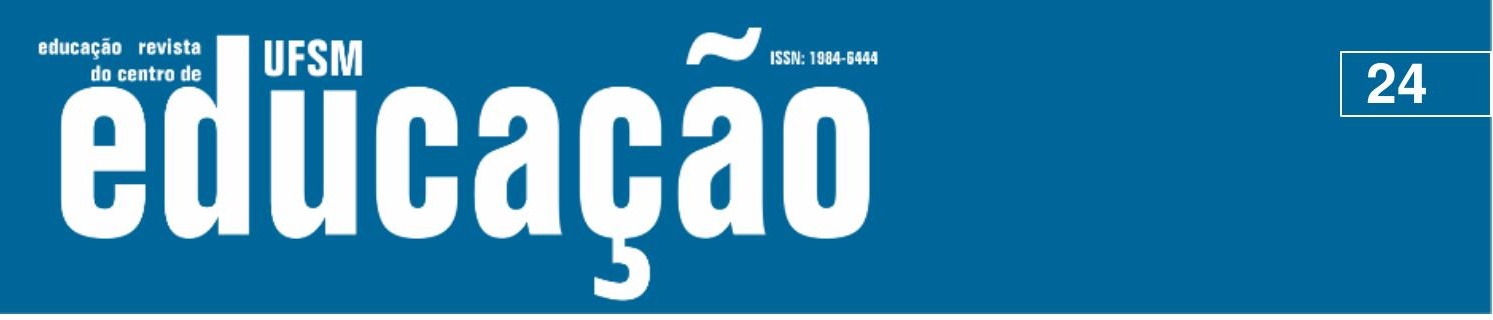

ISSN: 1984-6444 | http://dx.doi.org/10.5902/1984644438651

STEINER-KHAMSI, Gita. Globalization in Education: Real or imagined? In: STEINERKHAMSI Gita. (Org). The politics of educational borrowing and lending. New York: Teachers College Press, 2004.

STEINER-KHAMSI, Gita. Knowledge-Based Regulation and the Politics of International Comparison. Nordisk Pedagogik, v.29, p. 61-71, 2009.

STEINER-KHAMSI, Gita. Reterritorializing educational import: explorations into the politics of educational borrowing. In: NÓVOA, António. e LAWN, Martin. (Orgs). Fabricating Europe: the formation of an education space. London: Kluwer, 2002.

STEINER-KHAMSI, Gita. The economics of policy borrowing and lending: a study of late adopters. Oxford Review of Education, n.5, p. 665-678, 2006.

STOER, Stephen R.; CORTESÃO, Luiza. Critical inter/multicultural education and the process of transnationalization: a view from the semiperiphery. In: BALL, Stephen. J., GOODSON, Ivor e MAGUIRE, Meg. Education, Globalisation and New Times. Routledge, p.226-236, 2007.

TEODORO, António. Organizações internacionais e políticas educativas nacionais: A emergência de novas formas de regulação transnacional, ou uma globalização de baixa intensidade. In: STOER, Stephen. R., CORTESÃO, Luiza. e CORREIA, José Alberto (orgs). Transnacionalização da educação: da crise da educação à "educação da crise". Porto: Edições afrontamento, 2001.

WALFORD, Geoffrey. Privatization in industrialized countries. In: LEVIN, Henry (orgs). Privatizing education: can the marketplace deliver choice, efficiency, equity, and social cohesion? Colorado: Boulder, Westview, 2001.

\section{Correspondência}

Juares da Silva Thiesen - Universidade Federal de Santa Catarina - R. Eng. Agronômico Andrei Cristian Ferreira, s/n, CEP 88040-900, Trindade, Florianópolis, Santa Catarina, Brasil.

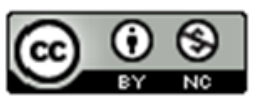

This work is licensed under a Creative Commons Attribution-NonCommercial 4.0 International (CC BY-NC 4.0)

\section{Notas}

\footnotetext{
${ }^{1} \mathrm{O}$ conceito de desnacionalização é tratado no texto Redes de escolas e modos de regulação do sistema educativo, por Justino e Batista (2013).
} 


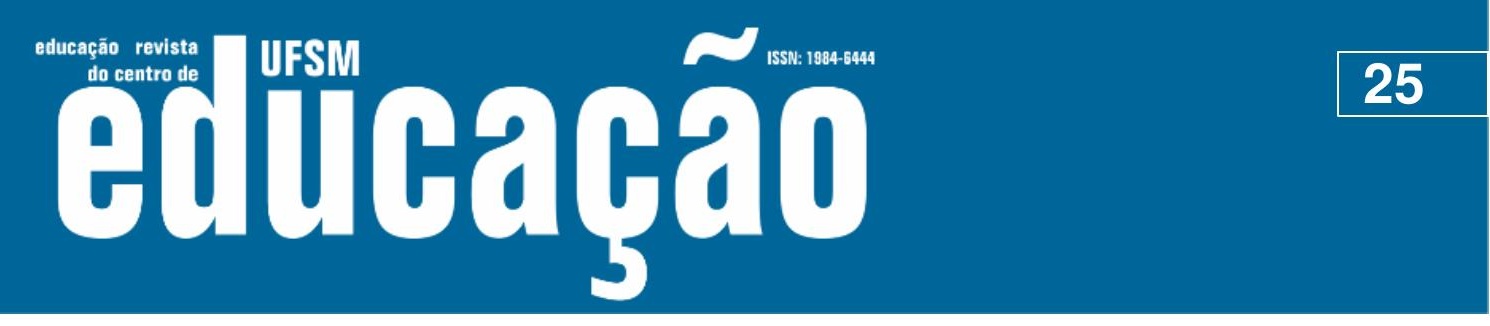

ISSN: 1984-6444 | http://dx.doi.org/10.5902/1984644438651

\begin{abstract}
${ }^{2} \mathrm{O}$ artigo forma parte do trabalho de pesquisa mais amplo desenvolvido na Universidade do Minho, cuja finalidade é analisar os impactos da internacionalização da educação superior sobre os currículos da Educação Básica em contextos de Brasil e Portugal. Os recortes de pesquisa explorados no âmbito da investigação mais ampla envolvendo o contexto brasileiro são respectivamente: i) elementos conceituais e contextuais da internacionalização da educação e do currículo; ii) estratégias de internacionalização presentes nos textos da política curricular brasileira; iii) discursos que se hegemonizam nos contextos dos organizamos multilaterais e nas redes políticas transnacionais; iv) potências do ideário cosmopolita em projetos de internacionalização da educação e, v) origens, motivações e projetos que mobilizam iniciativas de internacionalização no ensino básico em escala mundial.
\end{abstract}

${ }^{3}$ Para Lemos (2014), dentre as políticas públicas objeto de processos de transnacionalização, alguns autores consideram a política educativa uma das que tem sido objeto de maior atenção e onde a influência da globalização e da interdependência dos Estados mais se tem acentuado.

${ }^{4}$ A coexistência em vários países (de contextos geopolíticos tão diferentes) de discursos e medidas semelhantes indicia fenómenos de convergência que resultam, por um lado, dos processos de integração supranacional das economias e das políticas (conhecidos pela designação de "mundialização" ou "globalização") e, por outro lado, da permeabilidade do discurso político às retóricas de legitimação difundidas pelos centros de decisão e difusão internacionais, por meio daquilo que chamo de "efeito de contaminação" (Barroso, 2003, p. 84).

5 Para a busca dos textos nas bases de dados utilizamos alguns descritores (ou expressões), considerando sua inserção nos títulos, (e/ou) nas palavras chaves, (e/ou) nos resumos. Os descritores foram respectivamente: internacionalização, internacionalismo, transnacionalização, internacional, transnacional, mundial, mundialização, União Europeia, globalismo(s), supranacional, extranacional.

${ }^{6}$ Lemos (2014) destaca que a OCDE acompanhou sempre de perto a reforma, em interação com o ministério da educação português. Acentua que o próprio Veiga Simão refere que "a aposta permanente na internacionalização da Reforma Educativa conduziu a que a sua programação e planificação se desenvolvessem em intenso diálogo e estreita colaboração com a OCDE" (Simão, 2008) e em correspondência trocada com o autor em 2012, escreve que "a OCDE acompanhou a reforma em quase permanência.

7 Ver, por exemplo, Comunicação da Comissão das Comunidades Europeias (2002); Comissão das Comunidades Europeias (2007).

${ }^{8}$ António Teodoro destaca que no período compreendido entre o imediato pós-guerra e a adesão à CEE em 1 de janeiro de 1986, podem localizar-se relações privilegiadas das autoridades portuguesas com distintas organizações internacionais com intervenção no campo educativo, as quais configuram dupla relação de legitimação e mandato, primeiro com a OCDE até 1974, depois com a UNESCO no período da crise revolucionária em 1974 e 1975, e por último com o Banco Mundial e novamente com a OCDE, no período da normalização que antecede a integração com a CEE (2001, p. 129).

9 Filipa Seabra informa que entre 2011 e 2014, Portugal esteve sob um programa de resgate financeiro da 'troika' constituída pelo Fundo Monetário Internacional (FMI), o Banco Central Europeu (BCE) e a Comissão Europeia (CE).

${ }^{10}$ Duas obras organizadas em 2001 foram importantes para aprofundar a discussão sobre as questões da globalização, da transnacionalização e da internacionalização da educação tendo Portugal como foco de análise. São Elas: Globalização, fatalidade ou utopia?, organizada por Boaventura de Sousa Santos e Transnacionalização da educação: da crise da educação à educação da crise, organizada por Stephen R Stoer, Luíza Cortesão e José A. Correia.

${ }^{11}$ Documentos oficiais consultados: Currículo do ensino básico e do ensino secundário para a construção de aprendizagens essenciais baseadas no perfil dos alunos (2017); Despacho n. ${ }^{\circ}$ 6478/2017 da Direção-Geral da Educação (DGE); Perfil dos Alunos à Saída da Escolaridade Obrigatória (2017); Processo de concepção das Aprendizagens Essenciais (AE) - Síntese (2017); Aprendizagens Essenciais, componentes do currículo (2017); Parecer sobre currículo dos ensinos básico e secundário (Conselho Nacional de Educação, 2018).

${ }^{12}$ No Parecer do CNE que define a sétima revisão curricular, encontra-se que as últimas revisões curriculares do ensino básico foram respectivamente em 2012, 2011, 2008, 2007 e 2002 e do Ensino Secundário em 2012, 2011, 
